\title{
AN IMPROVED SWAB FOR THE DETECTION OF THREADWORM OVA
} BY

\section{J. A. BOYCOTT}

(RECEIVED FOR PUBLICATION, JANUARY 6, 1949)

The following device has been found to have certain advantages over the N.I.H. swabs* in the detection of the ova of threadworms (Oxyuris vermicularis).

It consists of: (1) a wooden tongue depressor 6 in. by $\frac{3}{4}$ in. ; (2) a strip of cellophane approximately 3 in. by 1 in., the size of a microscope slide, doubled over the end of the depressor and held in place by several turns of a rubber band; (3) a paper envelope: a " pay envelope," 2 in. by 4 in., is suitable.

Swabbing is most effective if done immediately the patient wakes in the morning. The swab

* Hall, M.C. (1937). Amer. J. trop. Med. 17, 445. should be rubbed along the peri-anal folds using pressure just short of causing pain. It is then replaced in the envelope, on which it is convenient to write the patient's name. In the laboratory the cellophane is removed, opened out, and placed on a slide; a drop of Canada balsam between slide and cellophane helps to keep the surface flat. Examination should be made under the $\frac{2}{3}$-in. objective and may be concentrated in the areas showing epithelial and faecal debris.

The single crease in the cellophane, the strength, and ease of packing have been found to be improvements on the N.I.H. swab. 